\title{
Strategies to Prioritize Clinical Options in Primary Care
}

\author{
Patrick J. O'Connor, MD, MA, MPH \\ JoAnn M. Sperl-Hillen, MD \\ Karen L. Margolis, MD, MPH \\ Thomas E. Kottke, MD, MSPH \\ HealthPartners Institute, Minneapolis, Minnesota \\ HealthPartners Center for Chronic Care Innovation, Minneapolis, Minnesota \\ Ann Fam Med 2017;15:10-13. https://doi.org/10.1370/afm.2027.
}

I n 2003, McGlynn and colleagues famously identified 439 clinical services recommended by subspecialists and others that, they argue, should be consistently delivered in primary care. ${ }^{1}$ Based on lengthy patient interviews and detailed chart audits, they estimated that US adults receive only $55 \%$ of these 439 recommended clinical services. They noted that the patients did not receive recommended clinical services, on average, 16 times, and that 1 patient was deficient in recommended services 304 times.

Yarnall et al reviewed US Preventive Services Task Force-recommended preventive services and estimated that a primary care clinician would need to spend 7.4 hours per working day to deliver recommended preventive services to a panel of patients ${ }^{2}$; doing so would, of course, leave little time for anything else and lead to frustrated clinicians and dissatisfied patients. What is a primary care clinician to do? We are damned if we do not deliver all evidence-based preventive and chronic disease care services with robot-like consistency and sleepless if we do. Proposed remedies include off-loading delivery of preventive or chronic disease care services to office staff, nurse case managers, subspecialty clinics, or even attractive-looking multicolored smartphone apps.

\section{The Case for Prioritization}

Perhaps a more reasonable and less-expensive strategy would be to prioritize clinical services related to preven-

Conflicts of interest: authors report none.

\section{CORRESPONDING AUTHOR}

Patrick J. O'Connor, MD, MA, MPH

HealthPartners Institute

Mail Stop 23301A

8170 33rd Ave S

Minneapolis, MN 55425

patrick.j.oconnor@healthpartners.com tive care and chronic disease care. In this issue of Annals of Family Medicine, Maciosek et al present compelling evidence that childhood immunizations and efforts to prevent or stop smoking are dominant population health priorities and rank numerous other services based on potential clinical benefit and cost-effectiveness. ${ }^{3-5}$ Once smoking cessation and immunizations are addressed, however, we are left wondering how to prioritize the other 439 evidence-based clinical services based on their potential benefit to an individual patient.

There are several fundamentally sound reasons to prioritize clinical services at the patient level. First, the value of even very strongly evidence-based clinical services varies across patients and with time. For example, the potential benefit of screening for colorectal, lung, cervical, and breast cancer varies up to tenfold based on patient-specific demographic, clinical, behavioral, and genetic factors. ${ }^{6}$ Likewise, the risks and benefits of intensive glucose control in patients with diabetes vary by age, comorbid conditions, cardiovascular risk, distance from personalized glycated hemoglobin $\left(\mathrm{HbA}_{1 \mathrm{c}}\right)$ goal, and other factors. If an older patient with major comorbidities already on intensive glucose-lowering therapy is not at their personalized $\mathrm{HbA}_{\mathrm{cc}}$ goal, the risks of further intensifying glucose therapy may well exceed the benefits. ${ }^{7,8}$ The ranks provided by Maciosek et al, which are based on overall population health benefit, must be further personalized to assess relative benefit of these services to an individual patient.

Second, in very large clinical trials, very small clinical benefits may be statistically significant and thus be designated as being evidence based. With respect to cholesterol-lowering medications, the number of study participants who need to be treated with a statin for 5 years to prevent 1 heart attack can vary from 6 patients to more than 240 patients, depending on baseline cholesterol level and baseline coronary heart disease risk. ${ }^{9,10}$ 
In general, the number of patients who need to be treated to prevent 1 heart attack or 1 cancer death varies widely across various evidence-based clinical options.

Third, most clinical trials that assess efficacy of clinical options are limited to consenting patients who meet stringent eligibility requirements. Results observed in these highly selected patients may have low generalizability to most patients. Moreover, because patient eligibility criteria and research protocols are designed to minimize the likelihood of serious adverse events in clinical trials, serious adverse events may be much more common in community care than in published research studies. ${ }^{11}$

\section{How to Prioritize Evidence-Based Clinical Options}

Primary care clinicians have always intuitively prioritized treatment options, but both benefits and risks of treatment are often not estimated accurately. For some clinical services, such as smoking cessation and certain immunizations, intuition is adequate. But beyond smoking and immunizations, intuitive estimation of potential benefit of multiple clinical options is very challenging.

Several alternative methods are available to identify and prioritize evidence-based clinical options with the most potential benefit to a given patient at a given point in time. ${ }^{12} \mathrm{With}$ respect to cardiovascular risk factor management, risk prediction equations, such as the American College of Cardiology/American Heart Association (ACC/AHA) Cardiovascular Disease risk equations, ${ }_{13,14}$ can be used to estimate the benefit of various clinical actions using the following 3-step approach: (1) use the risk equation to estimate a person's cardiovascular risk using current clinical data, (2) run the risk equation again, replacing 1 suboptimal clinical value (eg, an elevated blood pressure) with a potentially improved clinical value (anticipated improved blood pressure after treatment), and (3) subtract the results to estimate the potential reduction in cardiovascular risk that may be achieved by better blood pressure control. The potential benefits associated with better blood pressure management, cholesterol management, smoking cessation, or other clinical options can then be similarly estimated and then prioritized based on potential clinical benefit. ${ }^{15,16}$

This approach to prioritization has a number of important limitations. Risk estimates are necessarily derived from groups of people and thus cannot precisely predict future risk for one person. The benefits of stopping smoking are not the same as the benefits of never having smoked. The full benefits of improved cardiovascular risk factor control do not kick in immediately, and benefit estimates assume that the improved risk factor control will be sustained.
Current cardiovascular risk prediction tools are based on relatively small cohort studies that began in the 1950s, when many current drug classes were not available, aspirin use was low, smoking rates were high, and cardiac care was primitive when judged by today's standards. ${ }^{17}$ For these and other reasons, the ACC/ $\mathrm{AHA}$ and most other cardiovascular risk equations are somewhat obsolete and tend to overestimate event and death rates. ${ }^{18}$ Despite such limitations, explicit estimation of benefits and risks of treatment options is usually far more accurate than intuitive risk estimation by either clinician or patient. ${ }^{19}$ The availability of large databases that include detailed clinical data on millions of patients and novel analytic approaches, such as marginal structural models and machine learning, will likely lead to improved risk prediction and prioritization methods in the near future. ${ }^{20-22}$ It may be difficult, however, to explain these complex statistical approaches to clinicians and patients, who thus may be skeptical of their results.

\section{How to Apply Prioritization in Practice}

The potential of electronic health records (EHRs) to improve care has long been recognized but rarely been realized. Prototype EHR-linked, Web-based clinical decision support systems that identify and prioritize clinical options, however, save time, satisfy clinicians, empower patients, have high use rates, and improve care are now up and running in several large health care systems. ${ }^{15,16}$ Web services that include risk prediction equations can receive patient-specific data that are automatically sent from an EHR, perform the multiple computations needed to estimate the relative benefits of alternative treatment options, and display patientspecific prioritized treatment options on the EHR screen within 1 second.

Presenting clinical options to the patient facilitates patient-centered care and shared decision making by informing the patient of clinical options with the most potential benefit and then empowering the patient to select their preferred option(s). Many patients will continue to decline clinical options of high benefit, such as smoking cessation, colorectal cancer screening, or statin treatment. Then we must respect our patient's preferences and remember that patient treatment preferences and readiness to change typically vary with time. ${ }^{23} \mathrm{Clin}$ ical decision support systems update and reprioritize evidence-based treatment options at each subsequent encounter, enabling patients to see progress in some areas and reconsider previous preferences in other areas.

Results of randomized trials show that systems improve blood pressure levels and glucose control in diabetes patients, smoking cessation in dental offices, identification of high blood pressure levels in adoles- 
cents, and screening for hepatitis B in high-risk populations, as well as reduce cardiovascular risk in adults at high risk but without a diagnosis of heart disease or diabetes. ${ }^{16}$ There is also evidence that such systems are cost-effective and may be cost saving to payers when used on a routine basis in large care delivery systems. ${ }^{24}$ These clinical decision support systems are used at $70 \%$ to $80 \%$ of targeted visits, have $94 \%$ primary care clinician satisfaction, and are now in use every day at 3 large health care delivery systems that provide care to 1.5 million patients.

\section{Future Challenges}

An ongoing major challenge is how to present quantitative risk and benefit information to patients in a comprehensible way. Health literacy and numeracy vary widely across patients, suggesting that presentation of information on potential risks and benefits of clinical actions should be customized to specific groups of patients. Development of effective strategies to clearly communicate risk and benefit information to those with low numeracy is very much a work in progress, and there is plenty of room for new ideas on how to advance this agenda. ${ }^{25}$

Another ongoing challenge is to develop prioritization methods that can compare benefits across diverse clinical domains. Will a patient who does not like to take a lot of pills benefit more from starting a statin or treating osteoporosis? Prioritizing across diverse clinical domains is challenging because the benefits of lipid and osteoporosis management are very different (reduced risk of a cardiovascular event or death on the one hand and reduced likelihood of fracture and disability on the other). The traditional resolution of this problem is to quantify all benefits in terms of qualityadjusted life expectancy (QALE). Neither clinicians nor patients, however, are usually fluent in the language of QALE, and benefits of even very effective treatments on QALE are often surprisingly small. For example, among patients with type 2 diabetes in the United Kingdom Prospective Diabetes Study study, ${ }^{27}$ intensive lipid control extends QALE 1.42 years, ${ }^{26}$ and intensive blood pressure control extends QALE about 1.16 years, ${ }^{26}$ but intensive glucose control extends QALE by only 0.27 years, and it did not improve QALE at all in the ACCORD Trial. ${ }^{8,28}$

Recent advances in health care informatics and risk prediction methods enable design of new and more effective types of EHR-linked, Web-based, real-time clinical decision support systems that have high use rates at targeted visits, have high clinician satisfaction rates, and improve patients' clinical outcomes. We anticipate that further progress may occur as risk prediction science improves, better methods of com- municating results to patients in customized ways are devised, and ways of prioritizing clinical options across a broader set of clinical domains are developed. ${ }^{3-5,13,29}$

To read or post commentaries in response to this article, see it online at http://www.annfammed.org/content/15/1/10.

Key words: disease, prevention $\varepsilon$ control; health services; economics; prioritization; health impact; cost-effectiveness; cost-savings; immunization; mass screening; behavioral counseling

Submitted November 18, 2016; submitted, revised, November 18, 2016; accepted November 29, 2016.

\section{References}

1. McGlynn EA, Asch SM, Adams J, et al. The quality of health care delivered to adults in the United States. N Engl J Med. 2003;348 (26):2635-2645.

2. Yarnall KS, Pollak KI, Østbye T, Krause KM, Michener JL. Primary care: is there enough time for prevention? Am J Public Health. 2003; 93(4):635-641.

3. Maciosek MV, LaFrance AB, Dehmer SP, et al. Updated priorities among effective clinical preventive services. Ann Fam Med. 2017; 15(1):14-22.

4. Maciosek MV, LaFrance AB, Dehmer SP, et al. Health benefits and cost-effectiveness of brief clinician tobacco counseling for youth and adults. Ann Fam Med. 2017;15(1):37-47.

5. Dehmer SP, Maciosek MV, LaFrance AB, Flottemesch TJ. Health benefits and cost-effectiveness of asymptomatic screening for hypertension and high cholesterol and aspirin counseling for primary prevention. Ann Fam Med. 2017;15(1):23-36

6. National Cancer Institute. Breast cancer risk assessment tool. https:// www.cancer.gov/bcrisktool/. Updated May 16, 2011. Accessed Nov 16, 2016.

7. Riddle MC, Ambrosius WT, Brillon DJ, et al; Action to Control Cardiovascular Risk in Diabetes Investigators. Epidemiologic relationships between A1C and all-cause mortality during a median 3.4year follow-up of glycemic treatment in the ACCORD trial. Diabetes Care. 2010;33(5):983-990.

8. Gerstein HC, Miller ME, Genuth S, et al; ACCORD Study Group. Long-term effects of intensive glucose lowering on cardiovascular outcomes. N Engl J Med. 2011;364(9):818-828.

9. Stone NJ, Robinson JG, Lichtenstein AH, et al; American College of Cardiology/American Heart Association Task Force on Practice Guidelines. 2013 ACC/AHA guideline on the treatment of blood cholesterol to reduce atherosclerotic cardiovascular risk in adults: a report of the American College of Cardiology/American Heart Association Task Force on Practice Guidelines. Circulation. 2014;129(25) (Suppl 2):S1-S45.

10. Chou R, Dana T, Blazina I, Daeges M, Jeanne TL. Statins for Prevention of Cardiovascular Disease in Adults: Evidence Report and Systematic Review for the US Preventive Services Task Force. JAMA. 2016;316(19):2008-2024.

11. Pathak RD, Schroeder EB, Seaquist ER, et al; SUPREME-DM Study Group. Severe hypoglycemia requiring medical intervention in a large cohort of adults with diabetes receiving care in U.S. integrated health care delivery systems: 2005-2011. Diabetes Care. 2016;39(3):363-370.

12. Woolf SH. Potential health and economic consequences of misplaced priorities. JAMA. 2007;297(5):523-526.

13. Goff DC Jr, Lloyd-Jones DM, Bennett G, et al; American College of Cardiology/American Heart Association Task Force on Practice Guidelines. 2013 ACC/AHA guideline on the assessment of cardiovascular risk: a report of the American College of Cardiology/American Heart Association Task Force on Practice Guidelines. Circulation. 2014;129(25)(Suppl 2):S49-S73. 
14. Lloyd-Jones DM, Huffman MD, Karmali KN, et al. Estimating longitudinal risks and benefits from cardiovascular preventive therapies among medicare patients: The Million Hearts Longitudinal ASCVD risk assessment tool: a special report from the American Heart Association and American College of Cardiology. Circulation. 2016;(Nov):4.

15. O'Connor PJ, Sperl-Hillen JM, Fazio CJ, Averbeck BM, Rank BH, Margolis KL. Outpatient diabetes clinical decision support: current status and future directions. Diabet Med. 2016;33(6):734-741.

16. O'Connor PJ, Sperl-Hillen JM, Rush WA, et al. Impact of electronic health record clinical decision support on diabetes care: a randomized trial. Ann Fam Med. 2011;9(1):12-21.

17. Ford ES, Ajani UA, Croft JB, et al. Explaining the decrease in U.S. deaths from coronary disease, 1980-2000. N Engl J Med. 2007;356(23):2388-2398.

18. Rana JS, Tabada GH, Solomon MD, et al. Accuracy of the atherosclerotic cardiovascular risk equation in a large contemporary, multiethnic population. J Am Coll Cardiol. 2016;67(18):2118-2130.

19. Romo RD, Lee SJ, Miao Y, Boscardin WJ, Smith AK. Subjective, objective, and observed long-term survival: a longitudinal cohort study. JAMA Intern Med. 2015;175(12):1986-1988.

20. Hernán MA, Robins JM. Using big data to emulate a target trial when a randomized trial is not available. Am J Epidemiol. 2016;183(8):758-764.

21. Neugebauer R, Schmittdiel JA, Zhu Z, Rassen JA, Seeger JD, Schneeweiss $S$. High-dimensional propensity score algorithm in comparative effectiveness research with time-varying interventions. Stat Med. 2015;34(5):753-781.
22. Neugebauer R, Fireman B, Roy JA, Raebel MA, Nichols GA, $\mathrm{O}^{\prime}$ Connor PJ. Super learning to hedge against incorrect inference from arbitrary parametric assumptions in marginal structural modeling. J Clin Epidemiol. 2013;66(8)(Suppl):S99-S109.

23. Boyle RG, O'Connor PJ, Pronk NP, Tan A. Stages of change for physical activity, diet, and smoking among HMO members with chronic conditions. Am J Health Promot. 1998;12(3):170-175.

24. Gilmer TP, O'Connor PJ, Sperl-Hillen JM, et al. Cost-effectiveness of an electronic medical record based clinical decision support system. Health Serv Res. 2012;47(6):2137-2158.

25. Hargraves I, LeBlanc A, Shah ND, Montori VM. Shared Decision Making: The Need For Patient-Clinician Conversation, Not Just Information. Health Aff (Millwood). 2016;35(4):627-629.

26. Timbie JW, Hayward RA, Vijan S. Variation in the net benefit of aggressive cardiovascular risk factor control across the US population of patients with diabetes mellitus. Arch Intern Med. 2010;170(12):1037-1044.

27. Clarke PM, Gray AM, Briggs A, et al; UK Prospective Diabetes Study (UKDPS) Group. A model to estimate the lifetime health outcomes of patients with type 2 diabetes: the United Kingdom Prospective Diabetes Study (UKPDS) Outcomes Model (UKPDS no. 68). Diabetologia. 2004;47(10):1747-1759.

28. Ali MK, Feeney P, Hire D, et al. Glycaemia and correlates of patientreported outcomes in ACCORD trial participants. Diabet Med. 2012;29(7):e67-74.

29. Maciosek MV, Edwards NM, Coffield AB, et al. Priorities among effective clinical preventive services: methods. Am J Prev Med. 2006;31(1):90-96. 